\title{
Effect of Gamiondam-tang (GMODT), a Polyherbal Formula on the Pharmacokinetics Profiles of Tamoxifen in Male SD Rats
}

\author{
Eun-A Ryu ${ }^{1}$, Su-Jin Kang ${ }^{2,3}$, Chang-Hyun Song ${ }^{1,3}$, Bong-Hyo Lee ${ }^{3,4}$, Seong-Hun Choi ${ }^{1}$, \\ Chang-Hyun $\mathrm{Han}^{5}$, Young-Joon Lee ${ }^{2,3, *}$, Sae-Kwang $\mathrm{Ku}^{1,3, *}$ \\ ${ }^{1}$ Department of Anatomy and Histology, College of Korean Medicine, Daegu Haany University \\ ${ }^{2}$ Department of Preventive Medicine, College of Korean Medicine, Daegu Haany University \\ ${ }^{3}$ The Medical Research Center for Globalization of Herbal Medicine, College of Korean Medicine, \\ Daegu Haany University \\ ${ }^{4}$ Department of Meridian \& Acupoint, College of Korean Medicine, Daegu Haany University \\ ${ }^{5}$ Clinical Research Division, Korea Institute of Oriental Medicine
}

Objectives: The effects of Gamiondam-tang (GMODT) co-administration within 5min on the pharmacokinetics (PK) of tamoxifen were observed as a process of the comprehensive and integrative medicine, combination therapy of tamoxifen with GMODT to achieve synergic pharmacodynamics and reduce toxicity on the breast cancer.

Methods: After $50 \mathrm{mg} / \mathrm{kg}$ of tamoxifen treatment, GMODT $100 \mathrm{mg} / \mathrm{kg}$ was administered within $5 \mathrm{~min}$. The plasma were collected at $30 \mathrm{~min}$ before administration, $30 \mathrm{~min}, 1,2,3,4,6,8$ and $24 \mathrm{hrs}$ after end of GMODT treatment, and plasma concentrations of tamoxifen were analyzed using LC-MS/MS methods. PK parameters of tamoxifen (Tmax, Cmax, AUC, $t_{1 / 2}$ and MRT $_{\text {inf }}$ ) were analysis as compared with tamoxifen single administered rats using noncompartmental pharmacokinetics data analyzer programs.

Results: Co-administration with GMODT induced increased trends of plasma tamoxifen concentrations to $1 \mathrm{hr}$ after end of administration, and then showed decreased trends of plasma tamoxifen concentrations, and especially significant $(p<0.05)$ increases of plasma tamoxifen concentrations were demonstrated at $0.5 \mathrm{hr}$ after end of co-administration with GMODT and also related significant $(p<0.05)$ decreases of $\mathrm{AUC}_{0 \text {-inf }}$ and $\mathrm{MRT}_{\text {inf }}$ as compared with tamoxifen single formula treated rats, at dosage levels of tamoxifen $10 \mathrm{mg} / \mathrm{kg}$ and GMODT $100 \mathrm{mg} / \mathrm{kg}$ within $5 \mathrm{~min}$, in this experiment.

Conclusion: Based on the results of the present study, it is considered that single co-administration GMODT within 5 min significantly inhibited the oral bioavailability of tamoxifen through variable influences on the absorption and excretion of tamoxifen, can be influenced on the toxicity or pharmacodynamic of tamoxifen.

Key Words : Gamiondam-tang, Tamoxifen, Pharmacokinetics, Drug-drug interactions, Rat

\footnotetext{
- Received : 6 June $2017 \quad \cdot$ Revised : 22 June $2017 \quad \cdot$ Accepted : 22 June 2017

- Correspondence to : Young Joon Lee

Department of Preventive Medicine, College of Korean Medicine, Daegu Haany University

\#1 Haanydae-ro, Gyeongsan, Gyeongbuk, 38610, Republic of Korea

Tel : +82-53-819-1296, Fax : +82-53-819-1576, E-mail : gksxntk@dhu.ac.kr

- Correspondence to : Sae Kwang Ku

Department of Anatomy and Histology, College of Korean Medicine, Daegu Haany University

\#1 Haanydae-ro, Gyeongsan, Gyeongbuk, 38610, Republic of Korea

Tel : +82-53-819-1549, Fax : +82-53-819-1576, E-mail : gucci200@hanmail.net
} 


\section{Introduction}

Tamoxifen (Nolvadex ${ }^{\mathrm{TM}}$ ) is a nonsteroidal estrogen agonist-antagonist antineoplastic agent has been used for breast cancer ${ }^{1)}$. It is the usual endocrine (anti-estrogen) therapy for hormone receptor-positive breast cancer in pre-menopausal women, and is also a standard in post-menopausal women although aromatase inhibitors are also frequently used in that setting ${ }^{2,3)}$. In addition, tamoxifen also used to treat infertility in women with anovulatory disorders ${ }^{4,5)}$ and prevention for gynecomastia, ${ }^{6,7)}$ and bipolar disorder ${ }^{8,9)}$, as anti-angiogenesis $^{10)}$, control of gene expression ${ }^{11)}$, and treat Riedel thyroiditis ${ }^{12,13)}$ and Albright's syndrome ${ }^{14,15)}$. Tamoxifen is contraindicated, when used in women with ductal carcinoma in situ and women at high risk for breast cancer, concurrent anticoagulant therapy with a warfarin derivative ${ }^{16,17}$, and be used with caution in patients with leukopenia or thrombocytopenia ${ }^{18,19)}$ and pregnant ${ }^{20-22)}$. Hot flashes, vaginal discharge, menstrual irregularities and weight loss are common side effects related with tamoxifen treatment ${ }^{20,23,24)}$.

As results of combination therapies with other drugs to improve the side effects of tamoxifen or to achieve synergic effects, various drug-drug interactions of tamoxifen have been evaluated; because tamoxifen was metabolized by a substrate of CYP3A, 2C9, 2D6 $6^{25,26)}$, it interacted with various drugs, namely, combinations containing any of the following medications, depending on the amount present, may also interact with aminoglutethimide ${ }^{27)}$, anticoagulants $^{28,29)}$, bromocriptine ${ }^{30)}$, letrozole ${ }^{31)}$, medroxyprogesterone ${ }^{32)}$, phenobarbital ${ }^{33)}$, rifampin ${ }^{34)}$, and cyclosporine, erythromycin, diltiazem, erythromycin and nifedipine ${ }^{35-37)}$. However, interactions with herbal products have not been established except for some restricted natural compounds; tamoxifen enhanced warfarin effects, and it is contraindicate that co-administration of tamoxifen and wafarin ${ }^{28,29}$. In our previous studies, we have been observed the possible interactions with Korean traditional polyherbal formulas; we observed that oral co-administration of Jaeumkanghwa-tang, a traditional yin-tonifying herbal medicine has been used for various oriental obstetrical and gynecological fields within 5 min did not critically influenced on the pharmacokinetics profiles of tamoxifen after single ${ }^{38)}$ and repeated ${ }^{39)}$ co-administration at dosage levels of $50 \mathrm{mg} / \mathrm{kg}$ in tamoxifen and $100 \mathrm{mg} / \mathrm{kg}$ in Jaeumkanghwa-tang, respectively.

Gamiondam-tang (GMODT) consisted of 13 types of herbs - Pinelliae Rhizoma, Citri Unshii Pericarpium, Hoelen, Bambusae Caulis In Taeniam, Zingiberis Rhizoma Crudus, Ponciri Fructus, Polygalae Radix, Schizandrae Fructus, Ginseng Radix Alba, Rehmanniae Radix Preparata, Glycyrrhizae Radix et Rhizoma, Zizyphi Semen and Zizyphi Fructus and has been traditionally used to treat neuropsychiatric disorders such as neurosis and insomnia in traditional medicine ${ }^{40,41)}$. It has been reported that oral administration of GMODT improves cognitive function in aged rats through the increase of choline acetyltransferase expression in the basal forebrain ${ }^{42}$. Others also observed that GMODT prevents depressive behavior in thiamine-deficient mice and this may be closely related to the activation of cholinergic functions in the hippocampus ${ }^{43)}$. Although some researchers have investigated the pharmacological effects of GMODT, there has been no study on its possible drug-drug interactions with tamoxifen.

In the present study, the effects of GMODT co-administration on the pharmacokinetics of tamoxifen were observed as a process of the comprehensive and integrative medicine, combination therapy of tamoxifen with GMODT to achieve synergic pharmacodynamics and reduce toxicity on the breast cancer patients.

\section{Materials and methods}

\section{Animals and husbandry}


A total of twenty-one male Sprague-Dawley (SD) rats (6-wk old upon receipt; OrientBio, Seungnam, Korea) were used after acclimatization for 12 days. Animals were allocated five per polycarbonate cage in a temperature $\left(20-25^{\circ} \mathrm{C}\right)$ and humidity (40-45\%) controlled room. Light : dark cycle was $12 \mathrm{hr}: 12 \mathrm{hr}$ and feed (Samyang, Korea) and water were supplied free to access. After twelve days of acclimatization, five rats per group were selected based on the body weights, and used further experiments in the present study. All animals were marked by picric acid, and overnight fasted (about 18hrs; water was not restricted) before treatment, and further fasted during $3 \mathrm{hrs}$ after end of treatment. Animal experiments were conducted according to the international regulations of the usage and welfare of laboratory animals, and approved by the Institutional Animal Care and Use Committee in Daegu Haany University (Gyeongsan, Gyeongbuk, Korea) [Approval No. DHU2013-059].

\section{Test articles and formulation}

Reddish brown granules of GMODT (HANZUNG PHARM. CO. LTD., Daejeon, Korea), produced according to Korean Good Manufacturing Practice and permitted and regulated by the Korean Food \& Drug Administration (Seoul, Korea) were used in this experiment, and tamoxifen (Hangzhou Tacon Co., Ltd, Hangzhou, China) was used as control drug as listed follows. Individual compositions of ten kinds of herbs in GMODT were listed in Table 1. Tamoxifen and GMODT were stored in a refrigerator at $4^{\circ} \mathrm{C}$ to protect from light and degeneration until use. Both drugs are well dissolved (up to $20 \mathrm{mg} / \mathrm{ml}$ solutions in GMODT and up to $10 \mathrm{mg} / \mathrm{ml}$ solutions in tamoxifen) in distilled water as vehicle, respectively.

\section{Groupings and administration}

Five rats per group (two groups) were used in this study as follows. The doses of test materials were selected based on their toxicity and pharmacodynamics
$-50 \mathrm{mg} / \mathrm{kg}$ of tamoxifen with $100 \mathrm{mg} / \mathrm{kg}$ of GMODT. After $50 \mathrm{mg} / \mathrm{kg}$ of tamoxifen treatment, GMODT 100 $\mathrm{mg} / \mathrm{kg}$ was administered, within $5 \mathrm{~min}$. In tamoxifen single treated rats, $50 \mathrm{mg} / \mathrm{kg}$ of tamoxifen was orally administered, and then distilled water $5 \mathrm{ml} / \mathrm{kg}$ was orally administered, instead of GMODT solutions, 5 min-intervals. Each tamoxifen or GMODT was single orally administered, in a volume of $5 \mathrm{ml} / \mathrm{kg}$, dissolved in distilled water.

\section{Plasma collections}

All rats were anesthetized with 2 to $3 \%$ isoflurane (Hana Pharm. Co., Hwasung, Korea) in the mixture of $70 \% \mathrm{~N}_{2} \mathrm{O}$ and $28.5 \% \mathrm{O}_{2}$, and blood samples $(0.5$ $\mathrm{ml}$ ) were collected into $50 \mathrm{IU}$ heparinized tubes via the orbital plexus at $30 \mathrm{~min}$ before treatment (as a control), $30 \mathrm{~min}, 1,2,3,4,6,8$ and $24 \mathrm{hrs}$ after end of oral administration. Blood samples were immediately centrifuged for $10 \mathrm{~min}$ at $13,000 \mathrm{rpm}$ and about 0.3 $\mathrm{ml}$ aliquots of plasma were stored in a $-150^{\circ} \mathrm{C}$ deep freezer until analysis of tamoxifen.

\section{Sample preparation and calibrations}

Primary stock solution, $1.0 \mathrm{mg} / \mathrm{ml}$ of tamoxifen in $100 \% \mathrm{MeOH}$ (Baker, Phillipsburg, NJ, USA) and internal standard working solution, carbamazepine (Sigma-Aldrich, Sigma, St. Louise, MO, USA) 500 $\mathrm{ng} / \mathrm{ml}$ in acetonitrile were prepared. Working standard solutions were prepared by dilution with acetonitrile. All standard solutions were stored at $-20^{\circ} \mathrm{C}$ in the dark when not in use, and calibrated the standard samples as $100 \mu \mathrm{l}$ of blank plasma; working standard solutions and internal standard working solution were mixed with $200 \mu \mathrm{l}$ of acetonitrile. In addition, 100ul of sample plasma and internal standard working solution were mixed with $200 \mu \mathrm{l}$ of acetonitrile. The mixtures were mixed by vortex -mixing and centrifuged at $12,000 \mathrm{rpm}$ for $10 \mathrm{~min}$ at $4^{\circ} \mathrm{C}$. The clear supernatants $(5.0 \mathrm{\mu l})$ were transferred to injection vials and the aliquot was injected into 
the LC-MS/MS system.

\section{LC-MS/MS conditions}

Concentrations of tamoxifen in the rat plasma samples were determined LC-MS/MS method. Chromatographic analysis was performed using an Agilent 1100 Series HPLC (Agilent Technologies, Santa Clara, CA, USA) equipped with on-line degasser, binary pump, autosampler and column compartment. Separation of the analyte from potentially interfering material was achieved at ambient temperature using Waters Symmetry ${ }^{\mathrm{TM}} \mathrm{C} 18$ columns $(2.1 \times 50 \mathrm{~mm}, 3.5 \mu \mathrm{m})$ (Waters Corp., Milford, MA, USA) at column oven $30^{\circ} \mathrm{C}$. The mobile phase used for the chromatographic separation was composed of $50 \%$ distilled water $(0.1 \%$ formic acid) $/ 50 \%$ acetonitrile, and was delivered isocratically at a flow rate of $0.35 \mathrm{ml} / \mathrm{min}$. The column effluent was monitored using an API 2000 triple-quadruple mass-spectometric detector (Applied Biosystems, Foster City, CA, USA). The instrument was equipped with an electrospray interface in positive ion mode, and controlled by the Analyst version 1.4.1 software (Applied Biosystems, Foster City, CA, USA) (Linear $\left(1 / \mathrm{x}^{2}\right.$, no Iterate)). Samples were introduced to the interface through a Turbo IonSpray with the temperature set at $500^{\circ} \mathrm{C}$. A high positive voltage of $4.0 \mathrm{kV}$ was applied to the ion spray. Nitrogen was used as the nebulizer gas, curtain gas, and collision gas with the settings of 70,20 , and 7 , respectively. The multiple reaction monitoring (MRM) detection method was employed for the detection of tamoxifen; the transitions monitored were carbamazepine (IS): $\mathrm{m} / \mathrm{z}$ 237>194 (Retention time: 0.63min), tamoxifen: $372>178$ (Retention time: 0.55min). Calibration curves of tamoxifen were linear over the ranges studied with $r^{2}>0.999$. The lower limit of quantification of the tamoxifen in the rat plasma was $8 \mathrm{ng} / \mathrm{ml}$.

\section{Pharmacokinetic analysis}

The plasma concentration data were analyzed using a noncompartmental method on commercial pharmacokinetics data analyzer programs (PK solutions 2.0; Summit, Montrose, CO, USA) ${ }^{44,45)}$. The elimination rate constant $\left(\mathrm{K}_{\mathrm{el}}\right)$ was calculated by the log-linear regression of tamoxifen concentration data during the elimination phase, and the terminal half-life $\left(\mathrm{t}_{1 / 2}\right)$ was calculated by $0.693 / \mathrm{K}_{\mathrm{el}}$. The peak concentration (Cmax) and time to reach the peak concentration (Tmax) of tamoxifen in the plasma were obtained by visual inspection of the data in the concentration-time curve. The area under the plasma concentration-time curve $\left(\mathrm{AUC}_{0-\mathrm{t}}\right)$ from time zero to the time of the last measured concentration $\left(\mathrm{C}_{\text {last }}\right)$ was calculated using the linear trapezoidal rule ${ }^{46}$. The AUC zero to infinity ( $\mathrm{AUC}_{0 \text {-inf }}$ ) was obtained by adding $\mathrm{AUC}_{0-\mathrm{t}}$ and the extrapolated area was determined by $\mathrm{C}_{\text {last }} / \mathrm{K}_{\mathrm{el}}$. The mean residence time infinity $\left(\mathrm{MRT}_{\mathrm{inf}}\right)$ was calculated by dividing the first moment of $\mathrm{AUC}\left(\mathrm{AUMC}_{0 \text {-inf }}\right)$ by $\mathrm{AUC}_{0 \text {-inf. }}$.

\section{Statistical analyses}

All the means are presented with their standard deviation of five rats (Mean \pm S.D. of five rat plasma concentrations of tamoxifen). The pharmacokinetic parameters were compared using a non-parametric comparison test, Mann-Whitney U (MW) test, on the SPSS for Windows (version 14.0K, SPSS Inc., USA). A p-value $<0.05$ was considered statistically significant. In addition, the percent changes between tamoxifen single formula treated rats and tamoxifen with GMODT co-administered rats were calculated to help the understanding of the effects of co-administration: Percentage changes as compared with tamoxifen $50 \mathrm{mg} / \mathrm{kg}$ single treated mice $(\%)=$ [((Data of GMODT co-administrated rats - data of tamoxifen single formula treated rats)/Data of tamoxifen single formula treated rats) $\times 100$ ] 


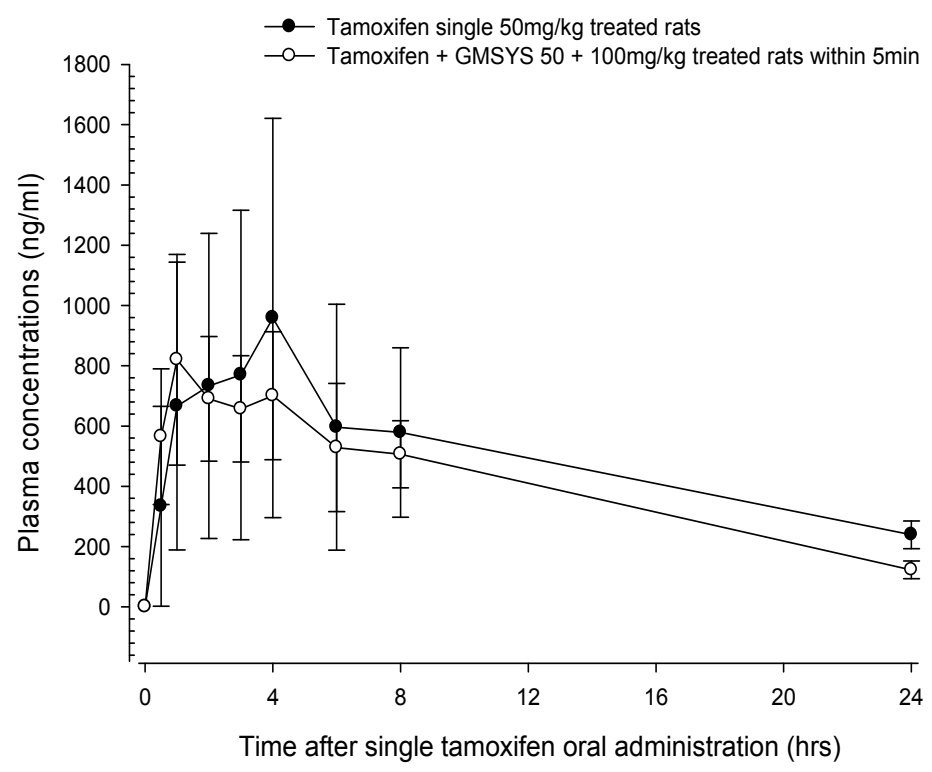

Fig. 1. Plasma concentrations of tamoxifen with and without GMODT co-administration within 5 min in male rats. Values are expressed as mean \pm S.D. of five rats $(\mathrm{ng} / \mathrm{ml})$. GMODT = Gamiondam-tang purchase from HANZUNG PHARM. CO. LTD. (Daejeon, Korea). * ${ }^{*} 0.05$ as compared with tamoxifen single treated.

Table 1. Composition of GMODT used in this Study

\begin{tabular}{|c|c|c|}
\hline Herbs & Scientific Names & Amounts (g) \\
\hline Pinelliae Rhizoma & Pinellia ternata (Thunb.) Breit. & 4.38 \\
\hline Citri Unshii Pericarpium & Citrus unshiu S.Marcov. & 2.75 \\
\hline Hoelen & Poria cocos Wolf & 1.25 \\
\hline Bambusae Caulis In Taeniam & Phyllostachys nigra var.henonis (Bean.) Stapf & 1.88 \\
\hline Zingiberis Rhizoma Crudus & Zingiber officinale Roscoe & 0.83 \\
\hline Ponciri Fructus & Poncirus trifoliata & 1.88 \\
\hline Polygalae Radix & Polygala tenuifolia Willd. & 1.25 \\
\hline Schizandrae Fructus & Schizandra chinensis (Turcz.) Baill & 1.25 \\
\hline Ginseng Radix Alba & Panax ginseng C.A.Meyer. & 1.25 \\
\hline Rehmanniae Radix Preparata & Rehmannia glutinosa Liboschitz ex Steudel & 1.25 \\
\hline Glycyrrhizae Radix et Rhizoma & Glycyrrhiza uralensis Fisch & 1.25 \\
\hline Zizyphi Semen & Zizyphus jujuba Miller & 1.25 \\
\hline Zizyphi Fructus & Zizyphus jujuba var. inermis (Bunge) Rehder & 0.76 \\
\hline Total & 13 types & 21.23 \\
\hline
\end{tabular}

\section{Results}

\section{Changes on the plasma concentrations of tamoxifen}

Tamoxifen was detected from $30 \mathrm{~min}$ to $24 \mathrm{hrs}$ after end of administration in the both tamoxifen single or co-administered rats with GMODT, respectively. Noticeable increases trends of plasma 
Table 2. Pharmacokinetic Parameters of Tamoxifen with and without GMODT Co-administration within 5 min in Male Rats

\begin{tabular}{lcc}
\hline & \multicolumn{2}{c}{ Tamoxifen $(50 \mathrm{mg} / \mathrm{kg})$} \\
\cline { 2 - 3 } Parameters & $\begin{array}{c}\text { Without GMODT co-administration } \\
\text { (Distill water) }\end{array}$ & $\begin{array}{c}\text { With GMODT co-administration } \\
(100 \mathrm{mg} / \mathrm{kg})\end{array}$ \\
\hline $\operatorname{Tmax}(\mathrm{hrs})$ & $4.60 \pm 1.95$ & $2.60 \pm 3.05$ \\
$\mathrm{Cmax}(\mu \mathrm{g} / \mathrm{ml})$ & $0.99 \pm 0.64$ & $0.87 \pm 0.29$ \\
$\mathrm{AUC}_{0-\mathrm{t}}(\mathrm{hr} \cdot \mu \mathrm{g} / \mathrm{ml})$ & $11.92 \pm 5.99$ & $9.89 \pm 2.29$ \\
$\mathrm{AUC}_{0-\mathrm{inf}}(\mathrm{hr} \cdot \mu \mathrm{g} / \mathrm{ml})$ & $18.02 \pm 3.81$ & $11.38 \pm 2.47^{*}$ \\
$\mathrm{t}_{1 / 2}(\mathrm{hr})$ & $18.65 \pm 12.67$ & $8.29 \pm 1.77$ \\
$\mathrm{MRT}_{\text {inf }}(\mathrm{hr})$ & $27.36 \pm 19.33$ & $11.41 \pm 1.83^{*}$ \\
\hline
\end{tabular}

Values are expressed as mean \pm S.D. of five rats. GMODT = Gamiondam-tang purchase from HANZUNG PHARM. CO. LTD. (Daejeon, Korea). * $\alpha 0.05$ as compared with tamoxifen single treated rats. Cmax: The peak plasma concentration; Tmax: Time to reach Cmax; AUC0-t: The total

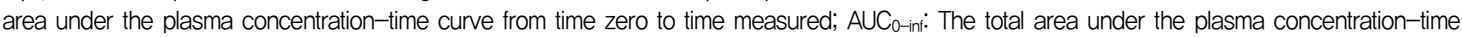
curve from time zero to time infinity; $t_{1 / 2}$ : half life; MRT $T_{\text {inf }}$ : mean residence to time infinity.

concentration of tamoxifen were demonstrated until $1 \mathrm{hr}$ after end of co-administration, but then decreased throughout blood collecting points, especially significant $(p<0.05)$ increases of the plasma tamoxifen concentrations were observed at $30 \mathrm{~min}$ after co-administration of GMODT and tamoxifen as compared with tamoxifen single treated rats, at a dosage levels of $100 \mathrm{mg} / \mathrm{kg}$ in GMODT and 50 $\mathrm{mg} / \mathrm{kg}$ in tamoxifen (Fig 1). The plasma tamoxifen concentrations at $30 \mathrm{~min}, 1,2,3,4,6,8$ and $24 \mathrm{hrs}$ after end of treatment were changed as $69.30,23.01$, $-5.86,-14.63,-26.95,-11.34,-12.47$ and $-48.66 \%$ in tamoxifen + GMODT treated rats as compared with tamoxifen single treated rats, respectively.

\section{Changes on the Tmax of tamoxifen}

The Tmax of tamoxifen were non-significantly and slightly decreased as $-43.48 \%$ in co-administrated rats with tamoxifen $50 \mathrm{mg} / \mathrm{kg}$ and GMODT $100 \mathrm{mg} / \mathrm{kg}$ $(2.60 \pm 3.05 \mathrm{hr})$ as compared with tamoxifen single treated rats $(4.60 \pm 1.95 \mathrm{hr})$, in the present study (Table 2).

\section{Changes on the Cmax of tamoxifen}

The Cmax of tamoxifen were non-significantly decreased as $-12.34 \%$ in co-administrated rats with tamoxifen $50 \mathrm{mg} / \mathrm{kg}$ and GMODT $100 \mathrm{mg} / \mathrm{kg}(0.87 \pm 0.29$ $\mu \mathrm{g} / \mathrm{ml})$ as compared with tamoxifen single treated rats $0.99 \pm 0.64 \mu \mathrm{g} / \mathrm{ml}$ ), in the present study (Table 2).

\section{Changes on the AUC of tamoxifen}

The $\mathrm{AUC}_{0-\mathrm{t}}$ of tamoxifen were non-significantly decreased as $-17.02 \%$ in co-administrated rats with tamoxifen $50 \mathrm{mg} / \mathrm{kg}$ and GMODT $100 \mathrm{mg} / \mathrm{kg}(9.89 \pm$ $2.29 \mathrm{hr} \cdot \mu \mathrm{g} / \mathrm{ml}$ ) as compared with tamoxifen single treated rats $(11.9216 \pm 5.99 \mathrm{hr} \cdot \mu \mathrm{g} / \mathrm{ml})$. In addition, $\mathrm{AUC}_{0 \text {-inf }}$ of tamoxifen were also significantly $(p<0.05)$ decreased as $-36.85 \%$ in co-administrated rats with tamoxifen and GMODT $(11.38 \pm 2.47 \mathrm{hr} \cdot \mu$ $\mathrm{g} / \mathrm{ml}$ ) as compared with tamoxifen single treated rats $(18.02 \pm 3.81 \mathrm{hr} \cdot \mu \mathrm{g} / \mathrm{ml})$, in the present study (Table 2).

\section{Changes on the $t 1 / 2$ of tamoxifen}

The $t_{1 / 2}$ of tamoxifen were markedly but non -significantly decreased as $-55.56 \%$ in co-administrated rats with tamoxifen $50 \mathrm{mg} / \mathrm{kg}$ and GMODT 100 $\mathrm{mg} / \mathrm{kg}(8.29 \pm 1.77 \mathrm{hr})$ as compared with tamoxifen single treated rats $(18.65 \pm 12.67 \mathrm{hr})$, in the present study (Table 2).

\section{Changes on the MRT inf of tamoxifen}

The $\mathrm{MRT}_{\text {inf }}$ of tamoxifen were markedly and significantly $(p<0.05)$ decreased as $-58.28 \%$ in co-administrated rats with tamoxifen $50 \mathrm{mg} / \mathrm{kg}$ and 
GMODT $100 \mathrm{mg} / \mathrm{kg}(11.41 \pm 1.83 \mathrm{hr})$ as compared with tamoxifen single treated rats $(27.36 \pm 19.33 \mathrm{hr})$, in the present study (Table 2).

\section{Discussion}

Co-administration with GMODT induced increased trends of plasma tamoxifen concentrations to $1 \mathrm{hr}$ after end of administration, and then showed decreased trends of plasma tamoxifen concentrations, and especially significant increases of plasma tamoxifen concentrations were demonstrated at $0.5 \mathrm{hr}$ after end of co-administration with GMODT and also related significant decreases of $\mathrm{AUC}_{0 \text {-inf }}$ and $\mathrm{MRT}_{\mathrm{inf}}$ as compared with tamoxifen single formula treated rats, at dosage levels of tamoxifen $10 \mathrm{mg} / \mathrm{kg}$ and GMODT $100 \mathrm{mg} / \mathrm{kg}$ within $5 \mathrm{~min}$, in this experiment. These findings are considered as direct evidences that GMODT significantly inhibited the oral bioavailability of tamoxifen through variable influences on the absorption and excretion of tamoxifen, can be influenced on the toxicity or pharmacodynamic of tamoxifen. Hence, it is recommended that pharmacokinetic studies should be tested like the effects of GMODT on the pharmacokinetics of tamoxifen, when they were co-administered with prolonger intervals than Tmax of tamoxifen oral administration (about 2.5 hr-intervals), to achieve the optimal dosing regimen of GMODT and tamoxifen co-administration, as a process of the comprehensive and integrative medicine, the combination therapy of tamoxifen with GMODT on the breast cancer.

Tamoxifen was absorbed slowly following oral administration and Tmax of tamoxifen occur about 3-6 hrs after a single $\operatorname{dose}^{47-49)}$ but it rapidly and extensively metabolized in the liver, through a substrate of CYP3A, 2C9, 2D626 including an active major metabolite, $\mathrm{N}$-desmethyltamoxifen has biologic activity similar to that of the parent $\operatorname{drug}^{50,51)}$. Steady-state concentrations of tamoxifen are attained after 3-4 weeks and those of N-desmethyltamoxifen, an active metabolite, are attained after 3-8 weeks ${ }^{52}$. Tamoxifen excreted principally in feces as polar conjugates $^{53)}$ with about 5-7 days of $t_{1 / 2}$ in tamoxifen and 9-14 days in $\mathrm{N}$-desmethyltamoxifen ${ }^{48)}$. Clearance of tamoxifen is higher in female children 2-10 years of age than in women ${ }^{54,55)}$. In the present study, Tmax of tamoxifen in tamoxifen single oral treated rats was detected as $4.60 \pm 1.95 \mathrm{hr}$, and $\mathrm{Cmax}, \mathrm{AUC}_{0-\mathrm{t}}$, $\mathrm{AUC}_{0 \text {-inf, }} \mathrm{t}_{1 / 2}$ and $\mathrm{MRT}_{\text {inf }}$ were detected as $0.99 \pm 0.64$ $\mu \mathrm{g}, 11.92 \pm 5.99 \mathrm{hr} \cdot \mu \mathrm{g} / \mathrm{ml}, 18.02 \pm 3.81 \mathrm{hr} \cdot \mu \mathrm{g} / \mathrm{ml}, 18.65 \pm$ $12.67 \mathrm{hr}$ and $27.36 \pm 19.33 \mathrm{hr}$, respectively. In tamoxifen with GMODT co-administered rats, Tmax, Cmax, $\mathrm{AUC}_{0-\mathrm{t}}, \mathrm{AUC}_{0 \text {-inf }}, \mathrm{t}_{1 / 2}$ and $\mathrm{MRT}_{\mathrm{inf}}$ of tamoxifen were detected as $2.60 \pm 3.05 \mathrm{hr}, 0.87 \pm 0.29 \mu \mathrm{g}, 9.89 \pm 2.29 \mathrm{hr} \cdot \mu$ $\mathrm{g} / \mathrm{ml}, \quad 11.38 \pm 2.47 \mathrm{hr} \cdot \mu \mathrm{g} / \mathrm{ml}, 8.29 \pm 1.77 \mathrm{hr}$ and $11.41 \pm$ $1.83 \mathrm{hr}$ as changed as $-43.48,-12.34,-17.02,-36.85$, -55.56 and $-58.28 \%$ as compared with tamoxifen 50 $\mathrm{mg} / \mathrm{kg}$ single oral treated rats, expecially significant decreases of $\mathrm{AUC}_{0 \text {-inf }}$ and $\mathrm{MRT}_{\text {inf }}$ were observed in GMODT and tamoxifen co-administrated rats at dosage levels of tamoxifen $10 \mathrm{mg} / \mathrm{kg}$ and GMODT $100 \mathrm{mg} / \mathrm{kg}$ within $5 \mathrm{~min}$, as compared with tamoxifen single formula treated rats.

Tamoxifen rapidly and extensively metabolized in the liver, through a substrate of CYP3A, 2C9, 2D626 to active major metabolite, $\mathrm{N}$-desmethyltamoxifen ${ }^{2,51)}$ and, therefore, tamoxifen can be interacted with various $\mathrm{drugs}^{27-37)}$. The severities of various side effects arise from tamoxifen treatment, especially bone $\operatorname{loss}^{56)}$, endometrial cancer ${ }^{57)}$, thromboembolism 58), fatty $\operatorname{liver}^{59)}$, reduced $\operatorname{cognition}^{60)}$, semantic memory scores $^{61)}$ and libido ${ }^{62,63)}$, premature growth plate fusion ${ }^{64)}$, immune suppression ${ }^{65,66)}$ and hypersensitivity $^{67,68)}$ are considered as directly co-related with absorption and excretion of tamoxifen or pharmacodynamics. In the present study, single co-administration of GMODT with tamoxifen within 5 min significantly inhibited the oral bioavailability and retention time of tamoxifen through variable influences on the absorption and excretion of 
tamoxifen, can be influenced on the toxicity or pharmacodynamic of tamoxifen. Hence, it is considered that pharmacokinetic studies should be tested like the effects of GMODT on the pharmacokinetics of tamoxifen, when they were co-administered with prolonger intervals than Tmax of tamoxifen oral administration, about 2.5 hr-intervals, to achieve the optimal dosing regimen of GMODT and tamoxifen co-administration, as a process of the comprehensive and integrative medicine, the combination therapy of tamoxifen with GMODT on the breast cancer.

\section{Conclusions}

Based on the results of the this study, it is considered that single co-administration GMODT within $5 \mathrm{~min}$ significantly inhibited the oral bioavailability of tamoxifen through variable influences on the absorption and excretion of tamoxifen, can be influenced on the toxicity or pharmacodynamic of tamoxifen. Therefore, it is recommended that pharmacokinetic studies should be tested like the effects of GMODT on the pharmacokinetics of tamoxifen, when they were co-administered with prolonger intervals than Tmax of tamoxifen oral administration (about 2.5 hr-intervals), to achieve the optimal dosing regimen of GMODT and tamoxifen co-administration, as a process of the comprehensive and integrative medicine, the combination therapy of tamoxifen with GMODT on the breast cancer.

\section{Acknowledgments}

This study was supported by grant of Korea of Health \& Welfare, Republic of Korea (Project No: 20-11-0-090-091-3000-3033-320).

\section{References}

1. The BIG 1-98 Collaborative Group. Letrozole therapy alone or in sequence with tamoxifen in women with breast cancer. The New England journal of medicine. 2009;361(8):766-76.

2. Jordan VC, Fourteenth Gaddum Memorial Lecture. A current view of tamoxifen for the treatment and prevention of breast cancer. British journal of pharmacology. 1993;110(2): 507-17.

3. Jordan VC. Tamoxifen (ICI46,474) as a targeted therapy to treat and prevent breast cancer. British journal of pharmacology. 2006;147 Suppl 1:S269-76.

4. Steiner AZ, Terplan M, Paulson RJ. Comparison of tamoxifen and clomiphene citrate for ovulation induction: a meta-analysis. Human reproduction (Oxford, England). 2005;20(6): 1511-5.

5. van Bommel EF, Hendriksz TR, Huiskes AW, Zeegers AG. Brief communication: tamoxifen therapy for nonmalignant retroperitoneal fibrosis. Annals of internal medicine. 2006;144(2):101-6.

6. Boccardo F, Rubagotti A, Battaglia M, Di Tonno P, Selvaggi FP, Conti G, et al., Evaluation of tamoxifen and anastrozole in the prevention of gynecomastia and breast pain induced by bicalutamide monotherapy of prostate cancer. Journal of clinical oncology : official journal of the American Society of Clinical Oncology. 2005;23(4):808-15.

7. Fradet Y, Egerdie B, Andersen M, Tammela TL, Nachabe M, Armstrong J, et al. Tamoxifen as prophylaxis for prevention of gynaecomastia and breast pain associated with bicalutamide $150 \mathrm{mg}$ monotherapy in patients with prostate cancer: a randomised, placebo-controlled, dose-response study. European urology. 2007;52(1):106-14.

8. Einat H, Yuan P, Szabo ST, Dogra S, Manji HK. Protein kinase $\mathrm{C}$ inhibition by tamoxifen antagonizes manic-like behavior in rats: implications 
for the development of novel therapeutics for bipolar disorder. Neuropsychobiology. 2007; 55(3-4): 123-31.

9. Amrollahi Z, Rezaei F, Salehi B, Modabbernia AH, Maroufi A, Esfandiari GR, et al. Double -blind, randomized, placebo-controlled 6-week study on the efficacy and safety of the tamoxifen adjunctive to lithium in acute bipolar mania. Journal of affective disorders. 2011; 129(1-3):327-31.

10. Blackwell KL, Haroon ZA, Shan S, Saito W, Broadwater G, Greenberg CS, et al. Tamoxifen inhibits angiogenesis in estrogen receptor-negative animal models. Clinical cancer research : an official journal of the American Association for Cancer Research. 2000;6(11):4359-64.

11. Feil R, Brocard J, Mascrez B, LeMeur M, Metzger D, Chambon P. Ligand-activated site-specific recombination in mice. Proceedings of the National Academy of Sciences of the United States of America. 1996;93(20):10887-90.

12. Dabelic N, Jukic T, Labar Z, Novosel SA, Matesa N, Kusic Z. Riedel's thyroiditis treated with tamoxifen. Croatian medical journal. 2003;44(2):239-41.

13. Fatourechi MM, Hay ID, McIver B, Sebo TJ, Fatourechi V. Invasive fibrous thyroiditis (Riedel thyroiditis): the Mayo Clinic experience, 1976-2008. Thyroid : official journal of the American Thyroid Association. 2011;21(7): 765-72.

14. Eugster EA, Shankar R, Feezle LK, Pescovitz $\mathrm{OH}$. Tamoxifen treatment of progressive precocious puberty in a patient with McCune-Albright syndrome. Journal of pediatric endocrinology \& metabolism : JPEM. 1999;12(5):681-6.

15. Sawathiparnich $P$, Osuwanaratana $P$, Santiprabhob J, Likitmaskul S. Tamoxifen improved final height prediction in a girl with McCune-Albright syndrome: patient report and literature review. Journal of pediatric endocrinology \& metabolism
: JPEM. 2006;19(1):81-6.

16. Redmond CK, Costantino JP. Design and current status of the NSABP breast cancer prevention trial. Recent results in cancer research. Fortschritte der Krebsforschung. Progres dans les recherches sur le cancer. 1996;140:309-17.

17. Fisher B, Costantino JP, Wickerham DL, Redmond CK, Kavanah M, Cronin WM, et al. Tamoxifen for prevention of breast cancer: report of the National Surgical Adjuvant Breast and Bowel Project P-1 Study. Journal of the National Cancer Institute. 1998;90(18):1371-88.

18. Lerner HJ, Band PR, Israel L, Leung BS, Phase II study of tamoxifen: report of 74 patients with stage IV breast cancer. Cancer treatment reports, 1976;60(10):1431-5.

19. Pienta KJ, Redman BG, Esper PS, Flaherty LE. A phase II evaluation of oral tamoxifen and intermittent intravenous vinblastine in hormone -refractory adenocarcinoma of the prostate. American journal of clinical oncology. 1996; 19(5):500-3.

20. Zeneca Pharmaceuticals. Nolvadex (tamoxifen citrate) prescribing information. 1998.

21. Kelly HL, Collichio FA, Dees EC. Concomitant pregnancy and breast cancer: options for systemic therapy. Breast disease. 2005;23:95-101.

22. Braems G, Denys H, De Wever O, Cocquyt V, Van den Broecke R. Use of tamoxifen before and during pregnancy. The oncologist. 2011; 16(11):1547-51.

23. Cella D, Fallowfield LJ. Recognition and management of treatment-related side effects for breast cancer patients receiving adjuvant endocrine therapy. Breast cancer research and treatment. 2008;107(2):167-80.

24. Karn A, Jha AK, Shrestha S, Acharya B, Poudel $\mathrm{S}$, Bhandari RB. Tamoxifen for breast cancer. JNMA; journal of the Nepal Medical Association. 2010;49(177):62-7.

25. Kim SY, Suzuki N, Santosh Laxmi YR, Rieger 
R, Shibutani S. a-hydroxylation of tamoxifen and toremifene by human and rat cytochrome P450 3A subfamily enzymes. Chemical research in toxicology. 2003;16(9):1138-44.

26. Notley LM, Crewe KH, Taylor PJ, Lennard MS, Gillam EM. Characterization of the human cytochrome P450 forms involved in metabolism of tamoxifen to its a-hydroxy and a,4-dihydroxy derivatives. Chemical research in toxicology. 2005;18(10):1611-8.

27. Lien EA, Anker G, Lønning PE, Solheim E, Ueland PM. Decreased serum concentrations of tamoxifen and its metabolites induced by aminoglutethimide. Cancer research. 1990;50(18): 5851-7.

28. Ritchie LD, Grant SM. Tamoxifen-warfarin interaction: the Aberdeen hospitals drug file. BMJ (Clinical research ed.). 1989;298(6682): 1253.

29. Tenni P, Lalich DL, Byrne MJ. Life threatening interaction between tamoxifen and warfarin. BMJ (Clinical research ed.). 1989;298(6666):93.

30. Lamberts SW, Verleun T, Hofland L, Oosterom R. Differences in the interaction between dopamine and estradiol on prolactin release by cultured normal and tumorous human pituitary cells. The Journal of clinical endocrinology and metabolism. 1986;63(6):1342-7.

31. Dowsett M, Pfister C, Johnston SR, Miles DW, Houston SJ, Verbeek JA, et al. Impact of tamoxifen on the pharmacokinetics and endocrine effects of the aromatase inhibitor letrozole in postmenopausal women with breast cancer. Clinical cancer research : an official journal of the American Association for Cancer Research. 1999;5(9):2338-43.

32. Reid AD, Horobin JM, Newman EL, Preece PE. Tamoxifen metabolism is altered by simultaneous administration of medroxyprogesterone acetate in breast cancer patients. Breast cancer research and treatment. 1992;22(2):153-6.
33. Dehal SS, Brodie AM, Kupfer D. The aromatase inactivator 4-hydroxyandrostenedione (4-OH-A) inhibits tamoxifen metabolism by rat hepatic cytochrome P-450 3A: potential for drug-drug interaction of tamoxifen and 4-OH-A in combined anti-breast cancer therapy. Drug metabolism and disposition: the biological fate of chemicals. 1999;27(3):389-94.

34. West CM, Reeves SJ, Brough W. Additive interaction between tamoxifen and rifampicin in human biliary tract carcinoma cells. Cancer letters. 1990;55(2):159-63.

35. Mani C, Gelboin HV, Park SS, Pearce R, Parkinson A, Kupfer D. Metabolism of the antimammary cancer antiestrogenic agent tamoxifen. I. Cytochrome P-450-catalyzed N-demethylation and 4-hydroxylation. Drug metabolism and disposition: the biological fate of chemicals. 1993;21(4):645-56.

36. Mani C, Pearce R, Parkinson A, Kupfer D. Involvement of cytochrome P4503A in catalysis of tamoxifen activation and covalent binding to rat and human liver microsomes. Carcinogenesis. 1994;15(12):2715-20.

37. Williams JA, Ring BJ, Cantrell VE, Jones DR, Eckstein J, Ruterbories $\mathrm{K}$, et al. Comparative metabolic capabilities of CYP3A4, CYP3A5, and CYP3A7. Drug metabolism and disposition: the biological fate of chemicals. 2002;30(8): 883-91.

38. Kwak MA, Park SJ, Park SH, Lee YJ, Ku SK. Effect of Jaeumkanghwatang (JEKHT), a Polyherbal Formula on the Pharmacokinetics Profiles of Tamoxifen in Male SD Rats (1) Single Oral Combination Treatment of Tamoxifen $50 \mathrm{mg} / \mathrm{kg}$ with JEKHT $100 \mathrm{mg} / \mathrm{kg}$ within $5 \mathrm{~min}$-. J Korean Med. 2016;37(2):1-11.

39. Park SJ, Kwak MA, Park SH, Lee YJ, Ku SK. Effect of Jaeumkanghwatang (JEKHT), a Polyherbal Formula on the Pharmacokinetics Profiles of Tamoxifen in Male SD Rats (2) - 
Oral Combination Treatment of Tamoxifen 50 $\mathrm{mg} / \mathrm{kg}$ with JEKHT $100 \mathrm{mg} / \mathrm{kg}$ on JEKHT 6-day Repeated Pretreated Rats with 8-day Repeated. J Soc Prev Korean Med. 2016;20(2):97-109.

40. Nakagawasai O, Yamadera F, Iwasaki K, Arai $\mathrm{H}$, Taniguchi R, Tan-No K, et al. Effect of kami-untan-to on the impairment of learning and memory induced by thiamine-deficient feeding in mice. Neuroscience. 2004;125(1):233-41.

41. Oh HK, Park SJ, Bae SG, Kim MJ, Jang JH, Ahn YJ, et al. Kami-ondam-tang, a traditional herbal prescription, attenuates the prepulse inhibition deficits and cognitive impairments induced by MK-801 in mice. Journal of ethnopharmacology. 2013;146(2):600-7.

42. Wang Q, Iwasaki K, Suzuki T, Arai H, Ikarashi $\mathrm{Y}$, Yabe $\mathrm{T}$, et al. Potentiation of brain acetylcholine neurons by Kami-Untan-To (KUT) in aged mice: implications for a possible antidementia drug. Phytomedicine : international journal of phytotherapy and phytopharmacology. 2000;7(4):253-8.

43. Nakagawasai O, Yamadera F, Iwasaki K, Asao T, Tan-No K, Niijima F, et al. Preventive effect of kami-untan-to on performance in the forced swimming test in thiamine-deficient mice: relationship to functions of catecholaminergic neurons. Behavioural brain research. 2007; 177(2):315-21.

44. Gibaldi M, Perrier D. Pharmacokinetics. 2nd ed. Taylor \& Francis. 1982.

45. Bailer AJ. Testing for the equality of area under the curves when using destructive measurement techniques. Journal of pharmacokinetics and biopharmaceutics. 1988;16(3):303-9.

46. Chiou WL. Critical evaluation of the potential error in pharmacokinetic studies of using the linear trapezoidal rule method for the calculation of the area under the plasma level--time curve. Journal of pharmacokinetics and biopharmaceutics. 1978;6(6):539-46.
47. Adam HK, Gay MA, Moore RH. Measurement of tamoxifen in serum by thin-layer densitometry. The Journal of endocrinology. 1980;84(1):35-42.

48. Adam HK, Patterson JS, Kemp JV. Studies on the metabolism and pharmacokinetics of tamoxifen in normal volunteers. Cancer treatment reports. 1980;64(6-7):761-4.

49. Fabian C, Sternson L, Barnett M. Clinical pharmacology of tamoxifen in patients with breast cancer: comparison of traditional and loading dose schedules. Cancer treatment reports. 1980;64(6-7):765-73.

50. Jordan VC, Bain RR, Brown RR, Gosden B, Santos MA. Determination and pharmacology of a new hydroxylated metabolite of tamoxifen observed in patient sera during therapy for advanced breast cancer. Cancer research. 1983; 43(3):1446-50.

51. Murphy C, Fotsis T, Pantzar P, Adlercreutz H, Martin F. Analysis of tamoxifen and its metabolites in human plasma by gas chromatography-mass spectrometry (GC-MS) using selected ion monitoring (SIM). Journal of steroid biochemistry. 1987;26(5):547-55.

52. Jordan VC. Metabolites of tamoxifen in animals and man: identification, pharmacology, and significance. Breast cancer research and treatment. 1982;2(2):123-38.

53. Sun D, Sharma AK, Dellinger RW, Blevins -Primeau AS, Balliet RM, Chen G, et al. Glucuronidation of active tamoxifen metabolites by the human UDP glucuronosyltransferases. Drug metabolism and disposition: the biological fate of chemicals. 2007;35(11):2006-14.

54. AstraZeneca Pharmaceuticals. Nolvadex (tamoxifen citrate) prescribing information. 2003.

55. Hall WA, Doolittle ND, Daman M, Bruns PK, Muldoon L, Fortin D, et al. Osmotic blood-brain barrier disruption chemotherapy for diffuse pontine gliomas. Journal of neuro-oncology. 2006;77(3):279-84. 
56. Vehmanen L, Elomaa I, Blomqvist C, Saarto T. Tamoxifen treatment after adjuvant chemotherapy has opposite effects on bone mineral density in premenopausal patients depending on menstrual status. Journal of clinical oncology : official journal of the American Society of Clinical Oncology. 2006;24(4):675-80.

57. Grilli S. Tamoxifen (TAM): the dispute goes on. Annali dell'Istituto superiore di sanita. 2006; 42(2):170-3.

58. Decensi A, Maisonneuve P, Rotmensz N, Bettega D, Costa A, Sacchini V, et al. Effect of tamoxifen on venous thromboembolic events in a breast cancer prevention trial. Circulation. 2005;111(5):650-6.

59. Osman KA, Osman MM, Ahmed MH. Tamoxifen-induced non-alcoholic steatohepatitis: where are we now and where are we going? Expert opinion on drug safety. 2007;6(1):1-4.

60. Paganini-Hill A, Clark LJ. Preliminary assessment of cognitive function in breast cancer patients treated with tamoxifen. Breast cancer research and treatment. 2000;64(2):165-76.

61. Eberling JL, Wu C, Tong-Turnbeaugh $\mathrm{R}$, Jagust WJ. Estrogen- and tamoxifen-associated effects on brain structure and function. NeuroImage. 2004;21(1):364-71.

62. Mortimer JE, Boucher L, Baty J, Knapp DL, Ryan E, Rowland JH. Effect of tamoxifen on sexual functioning in patients with breast cancer. Journal of clinical oncology : official journal of the American Society of Clinical Oncology. 1999;17(5):1488-92.

63. Cella D, Fallowfield L, Barker P, Cuzick J, Locker G, Howell A, et al. Quality of life of postmenopausal women in the ATAC ("Arimidex", tamoxifen, alone or in combination) trial after completion of 5 years' adjuvant treatment for early breast cancer. Breast cancer research and treatment. 2006;100(3):273-84.

64. Karimian E, Chagin AS, Gjerde J, Heino T, Lien EA, Ohlsson C, et al. Tamoxifen impairs both longitudinal and cortical bone growth in young male rats. Journal of bone and mineral research : the official journal of the American Society for Bone and Mineral Research. 2008;23(8):1267-77.

65. Wilson SC, Knight PG, Cunningham FJ. Evidence for the involvement of central conversion of testosterone to oestradiol-17b in the regulation of luteinizing hormone secretion in the cockerel. The Journal of endocrinology. 1983;99(2):301-10.

66. Nalbandian G, Paharkova-Vatchkova V, Mao A, Nale $\mathrm{S}$, Kovats $\mathrm{S}$. The selective estrogen receptor modulators, tamoxifen and raloxifene, impair dendritic cell differentiation and activation. Journal of immunology (Baltimore, Md. : 1950). 2005;175(4):2666-75.

67. Berstein LM, Wang JP, Zheng H, Yue W, Conaway M, Santen RJ. Long-term exposure to tamoxifen induces hypersensitivity to estradiol. Clinical cancer research : an official journal of the American Association for Cancer Research. 2004;10(4):1530-4.

68. Rousset-Jablonski C, Thalabard JC, Gompel A. Tamoxifen contraindicated in women with hereditary angioedema? Annals of oncology : official journal of the European Society for Medical Oncology / ESMO. 2009;20(7):1281-2. 